\title{
Erratum to: Prevalence of neurofibromatosis type 1 in congenital pseudarthrosis of the tibia
}

\author{
Kjell Van Royen ${ }^{1} \cdot$ Hilde Brems $^{2}$ - Eric Legius ${ }^{2}$ - Johan Lammens ${ }^{3}$ - Armand Laumen ${ }^{1}$
}

Published online: 6 May 2017

(C) Springer-Verlag Berlin Heidelberg 2017

Erratum to: Eur J Pediatr (2016) 175:1193-1198

DOI 10.1007/s00431-016-2757-z

The original version of this article, unfortunately, contained errors.

The first and family names of the authors were interchanged. The correct author names are now correctly presented in this article.

Kjell Van Royen

Kjell.Van.Royen@vub.ac.be

Hilde Brems

hilde.brems@med.kuleuven.be

Eric Legius

eric.legius@med.kuleuven.be

Johan Lammens

johan.lammens@uzleuven.be

Armand Laumen

armand.laumen@uzbrussel.be

1 Department of Orthopaedics and Traumatology, UZ Brussel,

Laarbeeklaan 101, 1090 Brussels, Belgium

2 Department of Human Genetics, KU Leuven, UZ Leuven,

Leuven, Belgium

3 Department of Orthopaedics, UZ Leuven, Leuven, Belgium 